\title{
Revista Contemporânea de Contabilidade: uma análise do perfil da produção acadêmica durante o período de 2004 a 2012
}

Journal of Contemporary Accounting: an analysis of the profile of academic production during the period 2004-2012

\section{Henrique César Melo Ribeiro}

Doutorando em Administração pela Universidade Nove de Julho (SP)

Professor da Faculdade Maurício de Nassau (Unidade Parnaíba-PI)

Endereço: Rua Guará, $n^{\circ}$ 23, Bairro Reis Veloso

CEP: 64.200-000 - Parnaíba/PI - Brasil

E-mail: hcmribeiro@hotmail.com ou hcmribeiro@gmail.com

Telefone: (86) 9543-8000

Artigo recebido em 10/03/2013. Revisado por pares em 03/04/2013. Reformulado em 26/04/2013. Recomendado para publicação em 06/05/2013 por Sandra Rolim Ensslin (Editora Científica). Publicado em 09/08/2013. 


\title{
Resumo
}

Este artigo explorou a produção acadêmica da Revista Contemporânea de Contabilidade durante o período de 2004 a 2012. O estudo baseou-se em um estudo de rede social e bibliométrico, utilizando-se da estatística descritiva em 133 artigos identificados. Os principais resultados deste estudo foram: predominância de artigos em parceria, sendo que Beuren e Colauto foram os autores que se destacaram como os mais profícuos, como também os que obtiveram maior centralidade de grau e de intermediação; constatação de que as IESs UFSC e USP foram as mais produtivas e de que a contabilidade de custos, ensino e pesquisa, assim como a contabilidade ambiental, de governança corporativa e desempenho organizacional foram os temas mais abordados.

Palavras-chave: Revista Contemporânea de Contabilidade. Produção Acadêmica. Rede Social. Bibliometria.

\begin{abstract}
This article explored the production of the academic Journal of Contemporary Accounting from 2004 to 2012. The present study was based on a study of bibliometric and social network using descriptive statistics, in 133 articles identified. The main results of this investigation were: the majority of articles had a partnership; Beuren and Colauto were the authors who stood out as the most useful, as well as those who obtained a higher centrality and intermediary degree. The higher education institutions (HEIs) of UFSC (in the state of Santa Catarina) and USP (in the state of São Paulo), were the most productive. Cost accounting, teaching and research, environmental accounting, corporate governance and organizational performance were the most covered topics.
\end{abstract}

Keywords: Journal of Contemporary Accounting. Academic Production. Social Network. Bibliometrics.

\section{Introdução}

O principal objetivo da ciência é a geração do conhecimento, sendo que a produção acadêmica e a disseminação dos resultados dessas pesquisas é um relevante impulsionador da expansão do saber (DIAS; BARBOSA NETO; CUNHA, 2011). A produção acadêmica, por sua vez, é um parâmetro de publicação em periódicos científicos, sendo o critério mais utilizado para se avaliar a contribuição, a evolução do conhecimento, relacionando-se com o surgimento, o fomento e a consolidação de grupos de pesquisa em diversas áreas (DANTAS et al., 2011), dessa forma, remetendo que a produção científica de uma área de conhecimento reflete o seu estado da arte e sua evolução. Nesse panorama, realça-se novamente a importância dos periódicos, que possuem uma função de destaque no que diz respeito à qualidade da pesquisa e ao avanço do conhecimento (MELI; OLIVEIRA NETO, 2011).

Nesse contexto, salienta-se que a ciência contábil no Brasil vem crescendo ao longo dos anos e sendo fortalecida com o empenho dos pesquisadores que buscam analisar e desvendar os problemas e fenômenos que ocorrem nessa ciência (MELI; OLIVEIRA NETO, 
p. 152, 2011). Ainda, a Bibliometria e a Análise de Redes Sociais vem ajudando a melhor compreender a produção científica em contabilidade no Brasil (MELI; OLIVEIRA NETO, 2011).

No que tange aos periódicos acadêmicos da área de contabilidade, destaca-se a Revista Contemporânea de Contabilidade (RCC) que, na nova classificação pelo Sistema Qualis da Capes (2010-2012), divulgada em 2012, recebeu a classificação B1 (RCC, 2013), o que indica uma grande evolução, já que no triênio anterior (2007-2009) a referida revista se encontrava no extrato B3. A revista iniciou suas publicações em 2004, e até 2012, 133 artigos foram publicados. Essa revista tem como missão:

\begin{abstract}
Interagir com diferentes públicos e instituições no que diz respeito aos conhecimentos contábeis, tanto em nível nacional como internacional, divulgar e fomentar o desenvolvimento de metodologias e procedimentos nas áreas do ensino, da pesquisa e da extensão em atividades contábeis, e contribuir para a formatação humana e profissional nos limites das discussões e possibilidades das Ciências Econômicas e Sócio-Aplicadas (RCC, 2013, p. $01)$.
\end{abstract}

O objetivo deste trabalho é explorar o que tem sido pesquisado e publicado na RCC, por meio das análises bibliométricas e de rede social. Esse objetivo justifica-se, pois o papel da academia é criar e disseminar conhecimento na sociedade, sendo que a produção acadêmica é a origem do ensino e da extensão (ROWE; BASTOS, 2010), remetendo a importância dos periódicos para a comunicação científica e para a avaliação dos pesquisadores (OLIVEIRA, 2002).

Ressalta-se que a bibliometria é uma ferramenta de pesquisa que analisa publicações em livros, relatórios e em revistas acadêmicas (FERREIRA, 2011). Esta pesquisa, portanto, focou na observação e nas técnicas bibliométricas (RAMOS-RODRÍGUEZ; RUÍZNAVARRO, 2004), bem como também na análise de redes sociais, a fim de avaliar a estrutura de relacionamento entre os autores (NERUR; RASHEED; NATARAJAN, 2008), as Instituições de Ensino Superior (IES) (FRANCISCO, 2011) e entre autores e IESs, simultaneamente, configurando, assim, uma rede two-mode (GUARIDO FILHO; MACHADO-DA-SILVA, 2010).

Alguns estudos similares ao que se propõe a fazer neste estudo já foram realizados, ou seja, trabalhos que tiveram o objetivo de investigar, mapear, explorar e/ou analisar especificamente periódicos acadêmicos da área de contabilidade, a saber: Leite Filho e Siqueira (2007), Barbosa et al. (2008), Batistella, Bonacim e Martins (2008), Espejo et al. (2009), Perdigão, Niyama e Santana (2010), Brunozi Júnior et al. (2011), Dantas et al. (2011), Ribeiro (2012) e Souza et al. (2012). Essas pesquisas mostram que aprender o estágio da produção acadêmica da área contábil em periódicos nacionais é preponderante para o fomento da área (BATISTELLA; BONACIM; MARTINS, 2008).

Diante disso, evidencia-se a questão de pesquisa que norteou este estudo: qual é o perfil da produção acadêmica da Revista Contemporânea de Contabilidade durante o período de 2004 a 2012? Para responder essa questão, objetiva-se explorar a produção acadêmica da Revista Contemporânea de Contabilidade durante o período de 2004 a 2012. Este trabalho, dessa forma, justifica-se por entender que mapear e conhecer trabalhos acadêmicos publicados em determinada área por meio de revisões sistemáticas é uma das maneiras de possibilitar a avaliação e a reflexão dessas publicações e da área em questão (CARDOSO et al., 2005). 
Este artigo está organizado em seis partes. A primeira parte evidencia a introdução, com a justificativa, a questão e o objetivo do trabalho. Em seguida, o referencial teórico será contemplado. Depois, serão expostos os procedimentos metodológicos usados na pesquisa. A quarta parte abordará, por sua vez, a análise e discussão dos resultados, sendo finalizada com a síntese das análises. Por fim, serão apresentadas as considerações finais, limitações da pesquisa e recomendações para estudos futuros.

\section{Referencial Teórico: Bibliometria, Rede Social e Pesquisas em Periódicos de Contabilidade}

As análises que buscam fornecer um mapeamento, de amplo escopo, sobre o que tem sido pesquisado e publicado sobre o tema contabilidade na Revista Contemporânea de Contabilidade foram feitas com base na bibliometria. Sob essa perspectiva, salienta-se que a bibliometria se desenvolveu mediante a elaboração de leis empíricas sobre o comportamento da literatura (EGGHE, 2005), as quais são mais utilizadas em trabalhos desse escopo. São elas: a Lei de Bradford, que enfatiza a produtividade dos periódicos e, portanto, o grau de relevância da revista, que é um aspecto bastante importante; a Lei de Lotka, que destaca a produtividade científica de autores, ou seja, o número de vezes que cada autor aparece citado em outros trabalhos científicos, por meio de um modelo de distribuição de tamanho/frequência em um conjunto de pesquisas, evidenciando aspectos de coautoria; e a Lei de Zipf, que conta as incidências de palavras que aparecem nos artigos científicos, como, por exemplo, as palavras-chave mais visualizadas nos artigos investigados.

Complementando a investigação bibliométrica, também foi utilizado neste trabalho um monitoramento das redes de coautoria (RAMOS-RODRÍGUEZ; RUÍZ-NAVARRO, 2004), a fim de compreender as ligações e conectividades entre os autores e suas respectivas IESs. O conceito de redes pode auxiliar na compreensão dos processos de interação social entre os autores e da própria geração do conhecimento. Nesse sentido, redes são um conjunto de nós e suas relações proporcionam interações e organizações sociais em que a informação e o conhecimento são elementos-chave desse processo (DIDRIKSSON, 2003).

Também se pode entender a rede social como um conjunto de pessoas, instituições ou organizações que, por possuírem afinidades em comum, compartilham, por exemplo, trabalho e/ou informações e, por meio dessas ligações, constroem e reconstroem uma estrutura social (TOMAÉL; MARTELETO, 2006). Sebastián (1999, p. 309) aprofunda esse conceito, trazendo-o para o campo da pesquisa científica como "[...] modalidade de redes de cooperação e [que] se definem pela associação de grupos de pesquisa para a realização de trabalhos conjuntos, geralmente por meio de projetos de Pesquisa e Desenvolvimento".

Para se analisar uma rede social, é necessária a compreensão da sua estrutura, assim como das relações que a compõem. A principal propriedade estrutural da rede é a densidade que, segundo Gnyawali e Madhavan (2001), pode ser entendida por meio da extensão da interconexão entre os autores, ou seja, quanto maior a interconexão, maior a densidade. Tratando-se das relações, a coesão entre os autores é o indicador mais representativo. As medidas de centralidade e densidade (CRUZ et al., 2011) compõem algumas das principais propriedades estruturais de uma rede.

Entre as centralidades, destacam-se a centralidade de grau (Degree), a centralidade de proximidade (Closeness) e a centralidade de intermediação (Betweenness) (MELI; 
OLIVEIRA NETO, 2011). A primeira é definida pelo número de laços adjacentes de um autor com relação aos outros em uma rede (WASSERMAN; FAUST, 1994), possibilitando uma avaliação da atividade local dos autores. A centralidade de proximidade (Closeness), por sua vez, é a função da proximidade ou distância de um autor em relação a todos os outros em uma rede. A ideia percebida na análise desse indicador é que um autor com elevada centralidade de aproximação é aquele que possui maiores condições de interagir rapidamente com todos os outros (HANNEMAN; RIDDLE, 2005; SCOTT, 2000; WASSERMAN; FAUST, 1994).

Por fim, cita-se a centralidade de intermediação (Betweenness), que avalia a dependência de autores não adjacentes de outros que atuam como uma espécie de ponte para efetivação da interação deles (FREEMAN, 1992). Nesse caso, quanto maior o grau de centralidade de intermediação, maior a probabilidade de controle de um autor sobre outros que dele dependem para executar a interação. Redes de conhecimento, assim como a maioria das redes sociais, têm na coesão um dos seus principais elementos de análise. Assim, no comportamento coletivo dos autores de um mesmo grupo, a coesão serve de base para a solidariedade e identidade do grupo.

Vale ressaltar que, neste estudo, foram usadas as análises bibliométricas e de rede social para mapear o perfil e a evolução da produção científica da Revista Contemporânea de Contabilidade no período de 2004 a 2012. Nesse contexto, a revisão da literatura identificou alguns trabalhos bibliométricos e/ou de rede social já realizados especificamente em revistas, ou seja, que já exploraram acervos de periódicos especificamente da área contábil.

Leite Filho e Siqueira (2007) descreveram e analisaram as principais características bibliométricas da Revista Contabilidade \& Finanças (USP), no período de 1999 a 2006 . Os resultados identificados pelos autores apontaram que, no período supracitado, houve predominância de autoria de gênero masculino, sendo que a colaboração entre dois autores (47\%) foi a forma mais frequente de autoria entre os trabalhos escritos, e que $76 \%$ dos autores tiveram apenas uma contribuição no periódico; nas referências bibliográficas, os autores enfatizaram livros $(40 \%)$, seguidos de artigos periódicos $(23 \%)$, onde foram encontrados indícios de endogenia com a maioria dos autores vinculados à USP. E os testes estatísticos sugeriram que a distribuição de autoria seguiu padrões da teoria bibliométrica (Lei de Lotka).

Barbosa et al. (2008) analisaram os artigos da Revista Brasileira de Contabilidade do período de 2003 a 2006, por meio de uma aplicação bibliométrica. Verificaram um declínio do número de trabalhos publicados, além de uma constante publicação de artigos com uma única autoria, e destacaram a presença de $72 \%$ de homens como autores, bem como a presença de $35 \%$ de articulistas com título de mestre. A análise das referências permitiu verificar que uma pequena consulta a fontes internacionais e que as quantidades de fontes consultadas veio aumentando durante o período analisado. Por fim, os pesquisadores constataram que muito se tem a discutir para ter a $\mathrm{RBC}$ em destaque na produção acadêmica contábil.

Batistella, Bonacim e Martins (2008) apreenderam o estágio da produção acadêmica na área contábil por meio do mapeamento de dois periódicos, a saber: Contabilidade \& Finanças (FEA-USP) e Revista Base (Unisinos). Os resultados observados pelos pesquisadores sugeriram que a Revista Contabilidade \& Finanças (FEA-USP) apresenta, com relação ao quesito forma, um desempenho geral categorizado como bom, enquanto que a Revista Base (Unisinos) apresenta um desempenho mediano. Observou-se, também, uma maior concentração de autores nas publicações da Revista Contabilidade \& Finanças (FEA- 
USP) (recorrência) em relação à Revista Base (Unisinos). O autor Medeiros foi o que mais publicou na Revista Contabilidade \& Finanças e a autora Beuren se destacou na revista Base.

Espejo et al. (2009) analisaram as tendências temáticas e metodológicas de publicações veiculadas na Accounting, Organizations \& Society (AOS), na Revista Contabilidade \& Finanças (RCF) e na The Accounting Review (TAR), entre 2003 e 2007. Os resultados obtidos pelos autores sugeriram predominância da temática de usuários externos. Nos periódicos AOS e na TAR, a temática relativa aos usuários internos apresentou tendência de crescimento. Os autores perceberam maiores ocorrências de abordagem da racionalidade econômica, todavia, com tendência de queda. As abordagens de pesquisa comportamental e institucional mostraram-se, por outro lado, ascendentes. Os autores mais produtivos foram responsáveis por $14,1 \%$ da produção científica analisada. Apenas $2,6 \%$ dos autores obtiveram publicação em mais de um periódico. Os resultados encontrados sugerem o estabelecimento de um processo contínuo de pesquisa contábil no Brasil. Por fim, os pesquisadores constataram que os achados desse estudo não podem servir como base para inferências relativas a outros periódicos.

Perdigão, Niyama e Santana (2010) analisaram as características da revista Contabilidade, Gestão e Governança no período de 1998 a 2009. Os autores verificaram o predomínio de autoria em parceria, diversidade de origem dos autores, média de referências por artigo (houve 22,05 citações), sendo que o tema contabilidade gerencial se destacou nas pesquisas analisadas. Os autores ainda destacaram os temas contabilidade internacional, que remete para a harmonização das normas contábeis, contabilidade social e ambiental, contabilidade tributária e a governança corporativa, por serem também assuntos importantes no cenário nacional e internacional corporativo e acadêmico.

Brunozi Júnior et al. (2011) analisaram a distribuição, as características metodológicas, a evolução e a temática das publicações científicas no periódico Revista de Contabilidade \& Finanças da USP de 1989 a 2009. A avaliação da revista indicou a concentração de autores afiliados a USP, principalmente docentes doutores; entretanto, a partir de 2003 os autores observaram a participação de outras entidades nas publicações. O periódico apresentou evolução ao longo dos anos, sendo que se percebe a distinção das temáticas propostas nos artigos. Nesse contexto, verifica-se a predominância de estudos relacionados a Finanças e Contabilidade (29\%), Ensino de Contabilidade e Conhecimento (13\%), Contabilidade Clássica e Teoria da Contabilidade (12\%) e Sistemas de Informação, Comunicação e Evidenciação (11\%). Quando se considera a proposta metodológica diversificada dos estudos, observa-se, quanto aos fins, a endogenia de trabalhos descritivos, principalmente no que concerne aos primeiros anos da revista. Quanto aos meios, notou-se, entre 1989 e 2002, uma concentração de publicações de cunho bibliográfico e documental. O cenário é distinto entre 2003 e 2009 , em que predominaram estudos realizados com aporte de dados primários e/ou secundários, podendo-se classificá-los como empíricos.

Dantas et al. (2011) avaliaram a evolução do padrão da produção científica contábil no Brasil e nos Estados Unidos, entre 2001 e 2008, utilizando-se, para isso, dos benchmarks das seguintes revistas: Revista de Contabilidade e Finanças (RCF) e a The Accounting Review (TAR). Os testes trabalhados pelos autores revelaram que para a maior parte dos parâmetros analisados, não foram confirmadas as premissas de que as características da produção da RCF são equivalentes às da TAR ou evoluíram significativamente entre 2001 e 2008, aproximando-se dos parâmetros do periódico estadunidense. Dantas et al. (2011) realçam que os pesquisadores contábeis brasileiros precisam compreender algumas questões, aonde focam 
que o nosso padrão de comunicação científica não está aderente ao padrão internacional. Isso pode auxiliar a explicar o fato de que a produção contábil nacional tem pouca, ou quase nenhuma, inserção em periódicos internacionais.

Ribeiro (2012) investigou a produção científica do periódico Brazilian Business Review no período de 2004 a 2011. Os principais resultados identificados pelo autor foram a predominância de artigos em parceria; a constatação de que os autores Valcemiro Nossa, Ariovaldo dos Santos e Otávio Ribeiro de Medeiros são os mais prolíferos e que A. B. Lopes e M. E. Porter foram os pesquisadores mais citados; e a confirmação de que a Universidade de São Paulo foi a IES que mais publicou artigos. Constatou-se uma centralidade de rede tanto na coautoria como também nas IES. E as temáticas mais evidenciadas em oito anos de análise foram Finanças, Mercado de capitais, Marketing, Organização e Negócios e Contabilidade e Auditoria. Concluiu-se, além disso, que mesmo sendo uma revista nova na academia, a Brazilian Business Review, por meio de seu acervo, já retrata o universo da produção cientifica. Isso evidencia o amadurecimento e a importância desse periódico, servindo como fomentador e disseminador do conhecimento e do fluxo das informações científicas na literatura acadêmica nacional, mas mais especificamente nas áreas de administração, contabilidade e economia.

Souza et al. (2012) analisaram as características dos artigos publicados na Revista de Contabilidade do Mestrado em Ciências Contábeis da UERJ no período de 2003 a 2011. Os autores contemplaram os seguintes resultados: 115 artigos foram publicados no período analisado e existiu o predomínio de autores professores doutores do sexo masculino. Além disso, observaram que a UERJ e a UFSC foram as instituições que apresentaram o maior número de autores com artigos publicados e que o autor com o maior número de publicações na revista é Vicente M. Ripoll Feliu. Constataram, ainda, que existe o predomínio de artigos com natureza qualitativa, com referências brasileiras, e que os principais temas dos artigos foram Contabilidade Gerencial e Contabilidade Financeira. Observaram, sobretudo, que os autores desse periódico costumam realizar produções científicas com grande número de parcerias, fato que sugere que os artigos são resultados de um compartilhamento de experiências entre os autores e que as publicações de autores com titulação inferior ao doutorado não têm ganhado espaço nesse periódico.

Portanto, são cada vez mais comuns estudos utilizando técnicas bibliométricas para analisar periódicos (FRANCISCO, 2011). A RCC abordou tais técnicas de análise recentemente, por meio de estudos dos seguintes autores: Coelho e Silva (2007), Silva, Wanderley e Santos (2010), Cella, Rodrigues e Niyama (2011), Dantas et al. (2011), Dias, Barbosa Neto e Cunha (2011), Meli e Oliveira Neto (2011), Beuren, Pinto e Zonatto (2012) e Carneiro et al. (2012). Porém, não existem ainda estudos sobre o que tem sido pesquisado e publicado na própria RCC, sendo, dessa forma, esse o objetivo principal deste trabalho.

\section{Procedimentos Metodológicos}

A referida pesquisa teve como objetivo explorar a produção acadêmica da Revista Contemporânea de Contabilidade durante o período de 2004 a 2012. Para tanto, utilizou-se a técnica de análise da bibliometria, pois fornece ferramentas para mensurar as publicações científicas, que incluem, livros, anais de conferências e artigos em revistas científicas (MOREIRA, RICCIO; SAKATA, 2007). 
A bibliometria, portanto, é uma técnica de pesquisa que analisa publicações em livros, relatórios e artigos (FERREIRA, 2011), a fim de quantificar, analisar e avaliar a produção intelectual científica (RAMOS-RODRÍGUEZ; RUÍZ-NAVARRO, 2004), sintetizando-a (CHAMBERS, 2004), sendo, dessa forma, adequada ao objetivo deste estudo. Justifica-se o uso da análise bibliométrica por ela conseguir cobrir um período prolongado de tempo, ajudando, assim, a identificar informações importantes em Journals acadêmicos (NERUR; RASHEED; NATARAJAN, 2008), como o agrupamento bibliográfico e a análise das palavras-chave (FRANCISCO, 2011).

A bibliometria desenvolveu-se mediante a elaboração de leis empíricas sobre o comportamento da literatura (EGGHE, 2005). Nesse cenário, é importante conhecer as três leis básicas da bibliometria para um melhor entendimento dos dados. Elas são oriundas, respectivamente, de três pesquisadores que se destacam por suas importantes descobertas (Bradford, Zipf e Lotka), sendo assim, as mais comumente utilizadas e relacionadas à produtividade científica (EGGHE, 2005).

A Lei de Bradford mensura o nível de relevância dos periódicos sobre determinada área (ACEDO; CASILLAS, 2005). Já a Lei de Lotka descreve a produtividade e as citações de autores por meio de um modelo de distribuição de tamanho/frequência em um conjunto de pesquisas, evidenciando aspectos de coautoria (AMBONI; CAMINHA; ANDRADE, 2012). E a Lei de Zipf, calcula a quantidade de ocorrências das palavras em vários textos, gerando uma lista de terminações de um determinado assunto ou palavra, sendo utilizada para observar qual tema científico é mais evidenciado nos trabalhos (EGGHE, 2005).

Além da bibliometria, os procedimentos realizados envolveram também o exame das análises de rede, mas especificamente de coautorias (RAMOS-RODRÍGUEZ; RUÍZNAVARRO, 2004; NERUR; RASHEED; NATARAJAN, 2008) e de IESs (GONZALO et al., 2009; FRANCISCO, 2011), para uma melhor compreensão de suas respectivas conectividades.

Tal procedimento é justificado por entender que o conhecimento científico é construído socialmente (ROSSONI; HOCAYEN-DA-SILVA; JÚNIOR, 2008; GUARIDO FILHO; MACHADO-DA-SILVA; GONÇALVES, 2009), influenciado pelos pesquisadores e seus pares que compõem estruturalmente a rede de relações entre as Instituições de Ensino Superior (ROSSONI; HOCAYEN-DA-SILVA; JÚNIOR, 2008).

Este estudo, dessa maneira, caracteriza-se como uma pesquisa descritiva por apresentar a observação, classificação, análise e interpretação dos 133 artigos da RCC. A abordagem quantitativa deve-se ao emprego da quantificação no tratamento dos dados, por meio de técnicas estatísticas descritivas (RICHARDSON; PERES, 1989).

A coleta de dados se desenvolveu por meio de pesquisa documental, que se justifica por selecionar, organizar, tratar e interpretar informações que se encontravam em estado bruto e dispersas (BEUREN; LONGARAY, 2003). A pesquisa documental buscou informações de todos os artigos, por meio do site (Disponível em: $<$ http://www.periodicos.ufsc.br/index.php/contabilidade/issue/archive $>$ ) da Revista Contemporânea de Contabilidade. O universo da pesquisa foi composto por 133 artigos (Figura 1) publicados no período 2004 a 2012, sendo realizada a marcação de todos os 133 artigos. Tal marcação consistiu na identificação dos elementos que compõem o artigo (palavras-chave, autoria, IES, corpo principal) e que ajudarão a responder a questão de pesquisa deste estudo. Logo em seguida, foi construída uma estrutura de tabelas e matrizes para melhor mensurar os indicadores deste estudo. 


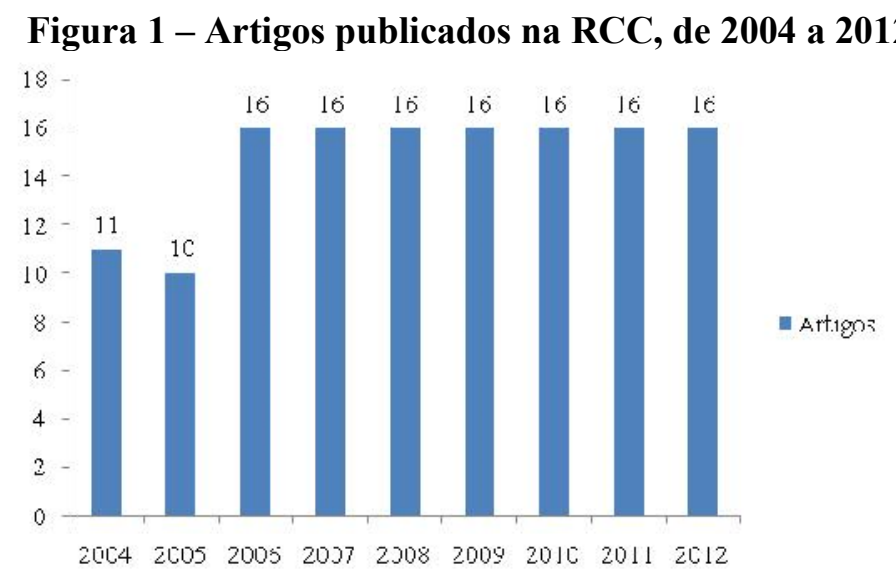

Fonte: Dados da pesquisa.

Com isso, foi realizada a análise dos seguintes indicadores: (i) características de autoria; (ii) autores com maior produção; (iii) IESs com maior produção; (iv) redes de coautoria; (v) rede social das IESs; (vi) frequência das palavras-chave; (viil) temas abordados; e (viii) abordagens e métodos de pesquisa. Tais indicadores foram calculados e capturados utilizando os softwares UCINET 6 for Windows, Microsoft Excel 2007 e Wordle.net, sendo este último aproveitado para calcular a frequência das palavras-chave.

\section{Análise e Discussão dos Resultados}

Este capítulo apresenta a análise bibliométrica e de rede social dos artigos publicados.

\subsection{Características de Autoria}

A Figura 2 mostra as características de autoria dos 133 artigos identificados na RCC.

Figura 2 - Autoria dos artigos

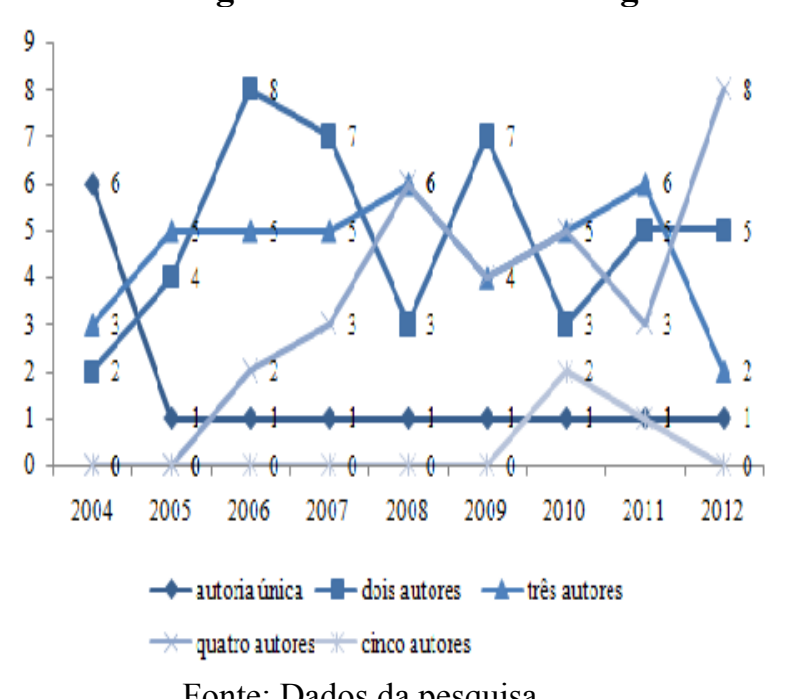

Fonte: Dados da pesquisa.
Figura 3 - Média de autoria

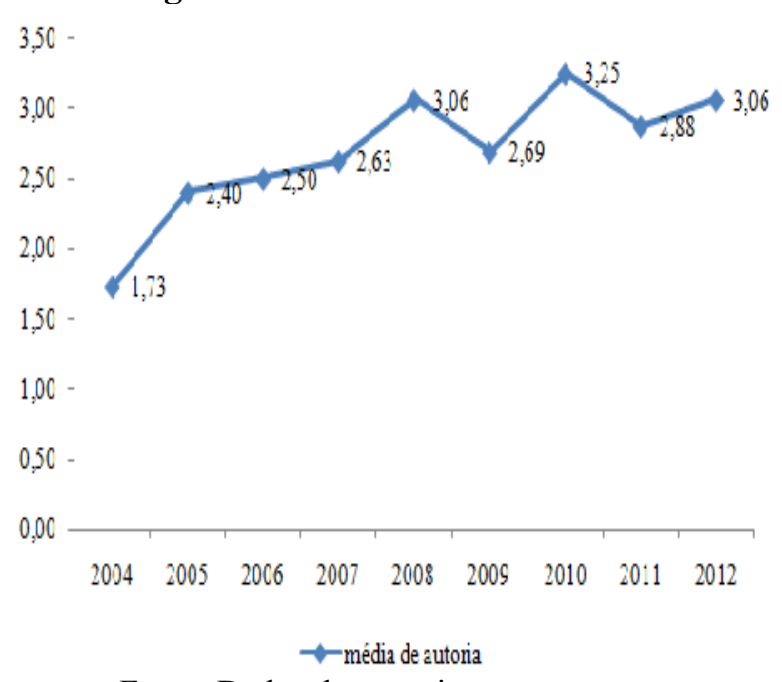

Fonte: Dados da pesquisa. 
Analisando a Figura 2, observa-se que $89,47 \%$ das publicações foram em parceria, sendo que entre elas, as predominantes foram com dois e três autores $(33,08 \%$ e 30,83\%, concomitantemente). A Figura 3, por sua vez, corrobora com os dados da Figura 2, ao evidenciar uma curva ascendente no que tange à média de autoria por artigo, conseguindo seu pico no ano de 2010, com 3,25 pesquisadores por artigo. Nesse panorama, é possível remeter às pesquisas similares de Leite Filho e Siqueira (2007) e Ribeiro (2012), os quais perceberam também a predominância de parceria entre os articulistas em seus respectivos estudos.

\title{
4.2 Autores com maior produção
}

A Figura 4, a seguir, evidencia os autores mais profícuos em nove anos de estudo na RCC.

Figura 4 - Autores com maior produção

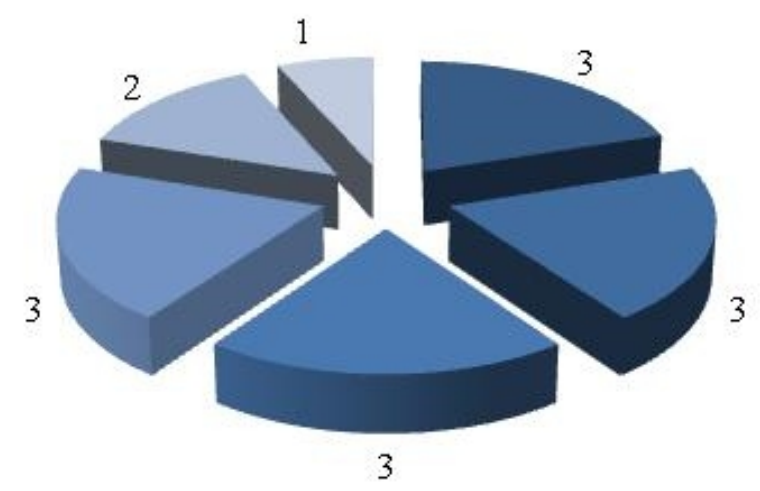

\author{
Ilse Maria Beuren - FURB \\ - Kárem Cristina de Sousa \\ Ribeiro - UFU \\ - Marcelo Alvaro da Silva \\ Macedo - UFRJ \\ Romualdo Douglas \\ Colauto - UFMG \\ in 38 autores com 2 \\ publicações \\ 276 autores com 1 \\ publicação
}

Fonte: Dados da pesquisa.

A Figura 4, conforme apresentado, destaca os autores Ilse Maria Beuren, Kárem Cristina de Sousa Ribeiro, Marcelo Alvaro da Silva Macedo e Romualdo Douglas Colauto como os pesquisadores que mais publicaram na RCC, todos com três artigos publicados cada. Em relação à autora Beuren, ela também foi realce no trabalho de Batistella, Bonacim e Martins (2008).

Ainda analisando a Figura 4, salienta-se que 38 articulistas publicaram 02 artigos, e que a grande maioria, ou seja, 276 autores, publicou apenas uma vez, o que equivale a $86,79 \%$, isto é, $13,21 \%$ dos autores publicaram mais de um artigo. Tal resultado vai ao encontro do estudo de Espejo et al. (2009), os quais observaram que os autores mais produtivos em sua pesquisa foram responsáveis por $14,1 \%$ da produção acadêmica analisada. É relevante, aqui, mencionar a Lei de Lotka (LEITE FILHO; SIQUEIRA, 2007), a qual dá evidência à produtividade científica de autores, ou seja, poucos publicam muito e muitos publicam pouco (EGGHE, 2005). 


\subsection{IESs com maior produção}

A Figura 5, a seguir, realça as 10 IESs mais produtivas em nove anos de estudo na RCC.

Figura 5 - IES com maior produção

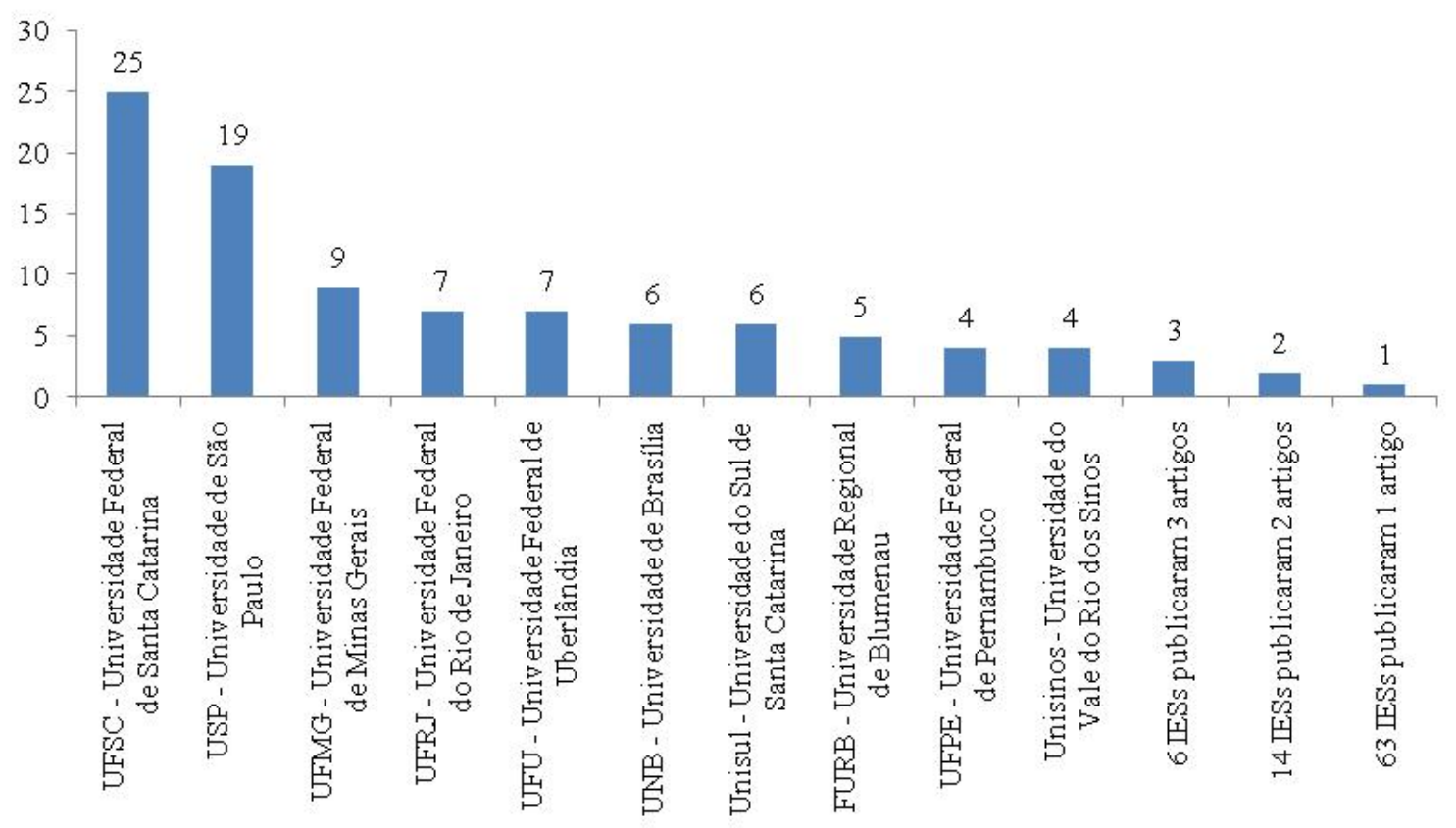

Fonte: Dados da pesquisa.

Verificando a Figura 5, observa-se que a Universidade Federal de Santa Catarina foi a IES mais profícua neste estudo, com 25 manuscritos publicados. Em seguida, ressalta-se a Universidade de São Paulo, com 19 publicações. Nesse cenário, salientam-se os trabalhos de Leite Filho e Siqueira (2007), Brunozi Júnior et al. (2011), Ribeiro (2012) e Souza et al. (2012), que dão destaque também à USP como IES mais produtiva em seus respectivos estudos.

Outras IESs são destacadas na Figura 5: a Universidade Federal de Minas Gerais (que publicou nove artigos); a Universidade Federal do Rio de Janeiro e a Universidade Federal de Uberlândia, ambas com sete papers publicados; a Universidade de Brasília e Universidade do Sul de Santa Catarina, ambas com seis publicações; a Universidade Regional de Blumenau, com cinco publicações; e a Universidade Federal de Pernambuco e Universidade do Vale do Rio dos Sinos, com quatro manuscritos publicados cada uma. Essas informações vão ao encontro do que foi mostrado na Figura 4, pois os quatro autores que mais publicaram são das seguintes IESs: FURB, UFU, UFRJ e UFMG.

Ainda analisando a Figura 5, nota-se que das 10 IESs mais profícuas, quatro são da Região Sudeste (USP, UFMG, UFRJ e UFU), quatro são da Região Sul (UFSC, Unisul, FURB e Unisinos), uma da Região Centro-Oeste (UNB) e uma da Região Nordeste (UFPE).

Em suma, 30 instituições publicaram de 2 a 25 artigos e 63 IESs publicaram apenas uma vez, equivalendo ao total de $67,74 \%$. 


\subsection{Redes de coautoria}

As Figuras 6 e 7, a seguir, visualizam as redes de coautoria dos 318 autores envolvidos em nove anos de pesquisa, sendo que a Figura 6 contempla a rede de coautoria com a centralidade de grau e a Figura 7, a rede de coautoria com a centralidade de intermediação.

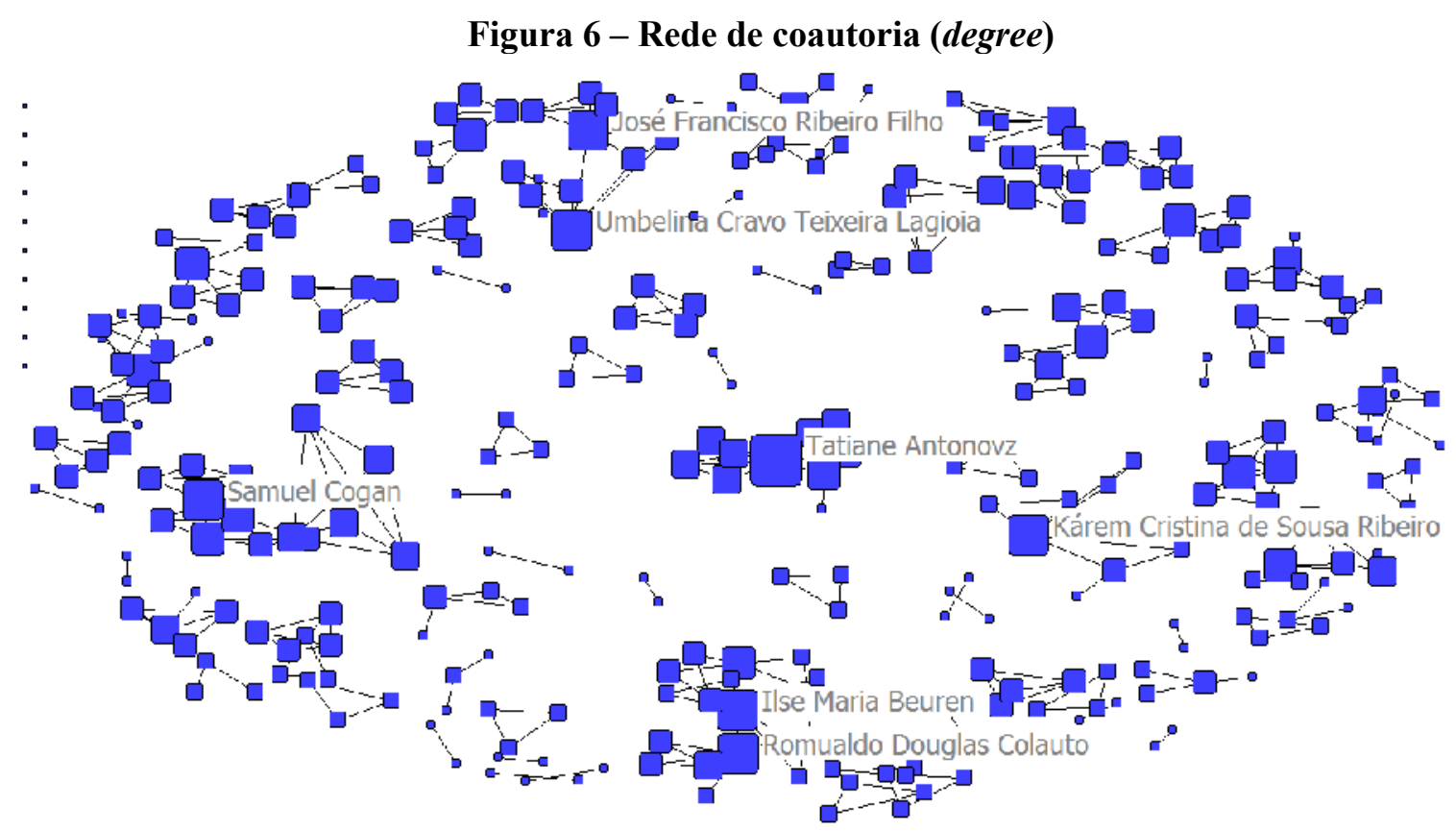

Fonte: Dados da pesquisa.

Verifica-se pela Figura 6 que a rede social dos autores configura-se com baixa interação, isto é, revela baixa centralização. Esse resultado pode ser corroborado quando se constata que a densidade total do grupo é de 0,0076 , ou seja, a rede realiza $0,76 \%$ do total de suas relações. Tal cenário não reflete o ideal quando se trata de redes de coautoria, já que os grupos encontram-se isolados, não tendo atores fazendo a ponte entre eles. Esses atores seriam responsáveis pela troca de conhecimento não redundante entre os grupos. Os estudos de Francisco (2011) e Ribeiro (2012) sobre redes de coautoria corroboram as informações visualizadas na Figura 6, pois observaram, em seus respectivos estudos, pouca interação entre os atores envolvidos nos trabalhos.

Ao se analisar os autores que se destacam na rede da Figura 6, percebe-se a importância de alguns, como Antonovz, Ribeiro, Beuren, Colauto, Cogan, Lagioia e Ribeiro Filho. Esses autores possuem alta centralidade de grau (degree), o que indica o maior número de relações na rede, ou seja, são aqueles que são mais procurados ou que procuram mais parceiros para a produção e publicação de artigos na RCC; entre eles, Beuren e Colauto aparecem como os mais profícuos deste estudo.

Ao se analisar a centralidade de intermediação (betweenness) na Figura 7, percebe-se a dispersão da rede, pois poucos autores representam essa medida, visto que a maior parte está localizada no seu componente principal. Os autores Beuren, Colauto, Antonovz, Ribeiro 
Filho, Lagioia, Ribeiro, Cogan, Diehl, Ott, Nuintin e Nakao são os maiores responsáveis pela troca da informação na rede.

Figura 7 - Rede de coautoria (betweenness)

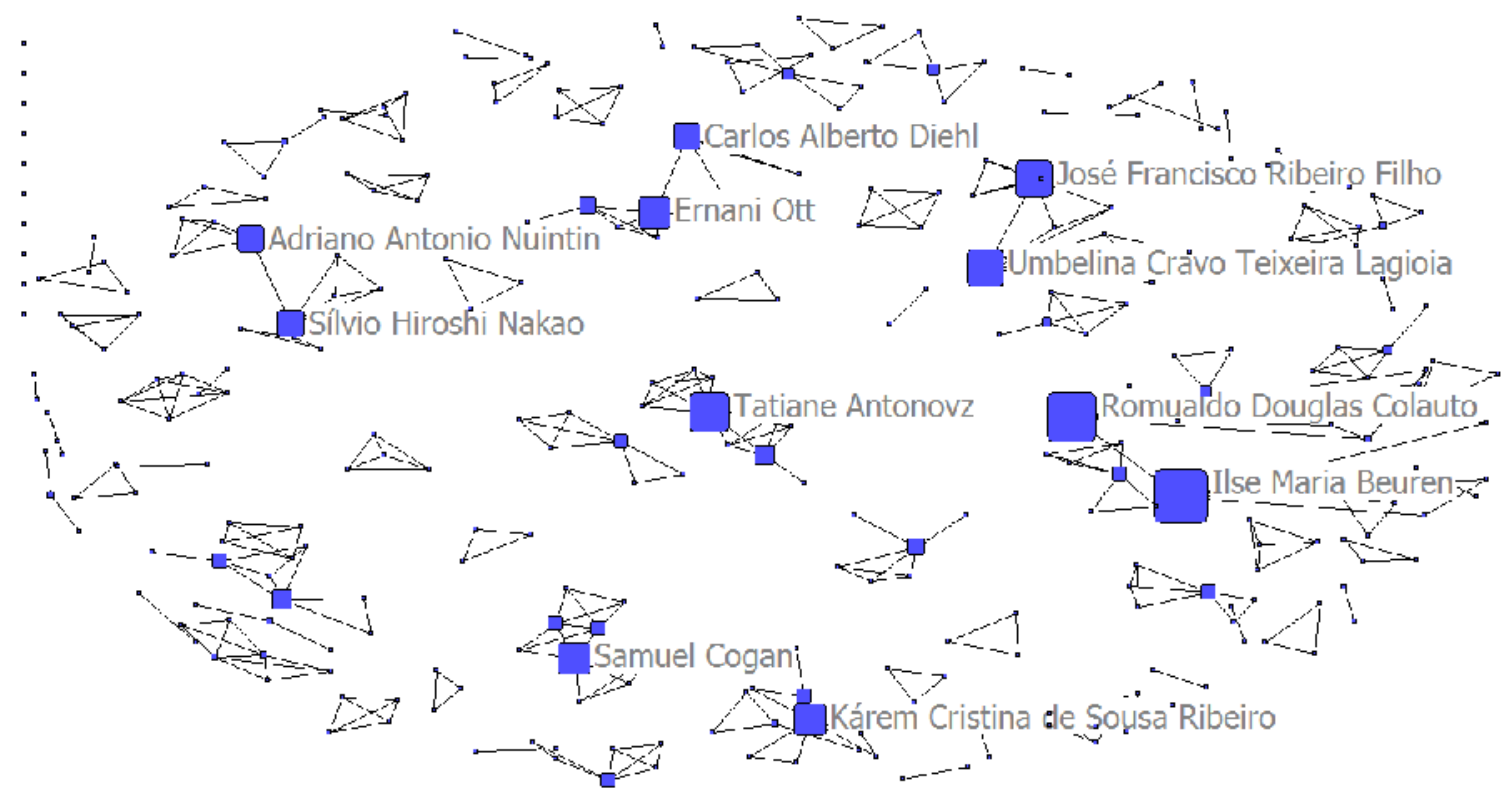

Fonte: Dados da pesquisa.

É interessante ressaltar a importância e o destaque da participação dos autores Beuren e Colauto, visto que ambos possuem alta centralidade de grau, assim como alta centralidade de intermediação neste estudo.

\subsection{Rede social das IESs}

Já as Figura 8 e 9, a seguir, apresentam as redes das 93 IESs, sendo que a Figura 8 visualiza a centralidade de grau destas IESs e a Figura 9 a centralidade de intermediação. Além dessas figuras, exalta-se também a Figura 10, que trabalha uma rede two-mode (LATAPY; MAGNIEN; DEL VECCHIO, 2008), evidenciando, neste estudo, os dados originais das redes dos autores e das IESs de maneira conjunta.

A Figura 8 concebe as 10 IESs mais centrais deste estudo no que se refere ao degree. São elas: USP, UFSC, Unisul, UFMG, FURB, Unesc, UFBA, UFPB, UFRG e Fucape, sendo que a USP, UFSC, UFMG, Unisul e FURB figuram também como as IESs que mais produziram artigos em nove anos de estudo. Ainda analisando a Figura 8, percebe-se uma centralidade da mesma, o que pode ser confirmado por sua densidade, que foi de 0,0192 , isto é, apenas $1,92 \%$ das relações estão sendo realizadas. 


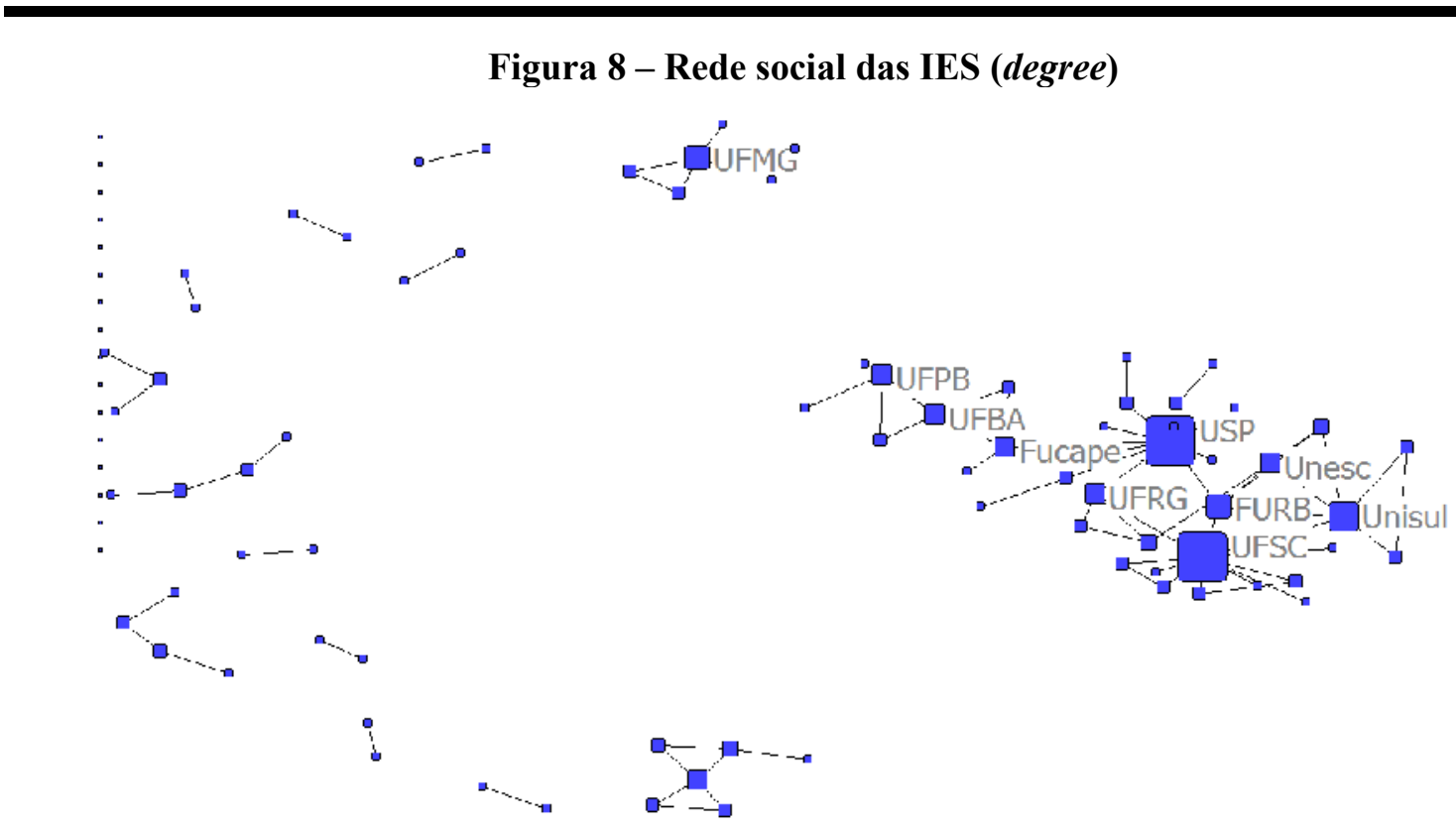

Fonte: Dados da pesquisa.

Figura 9 - Rede social das IES (betweenness)

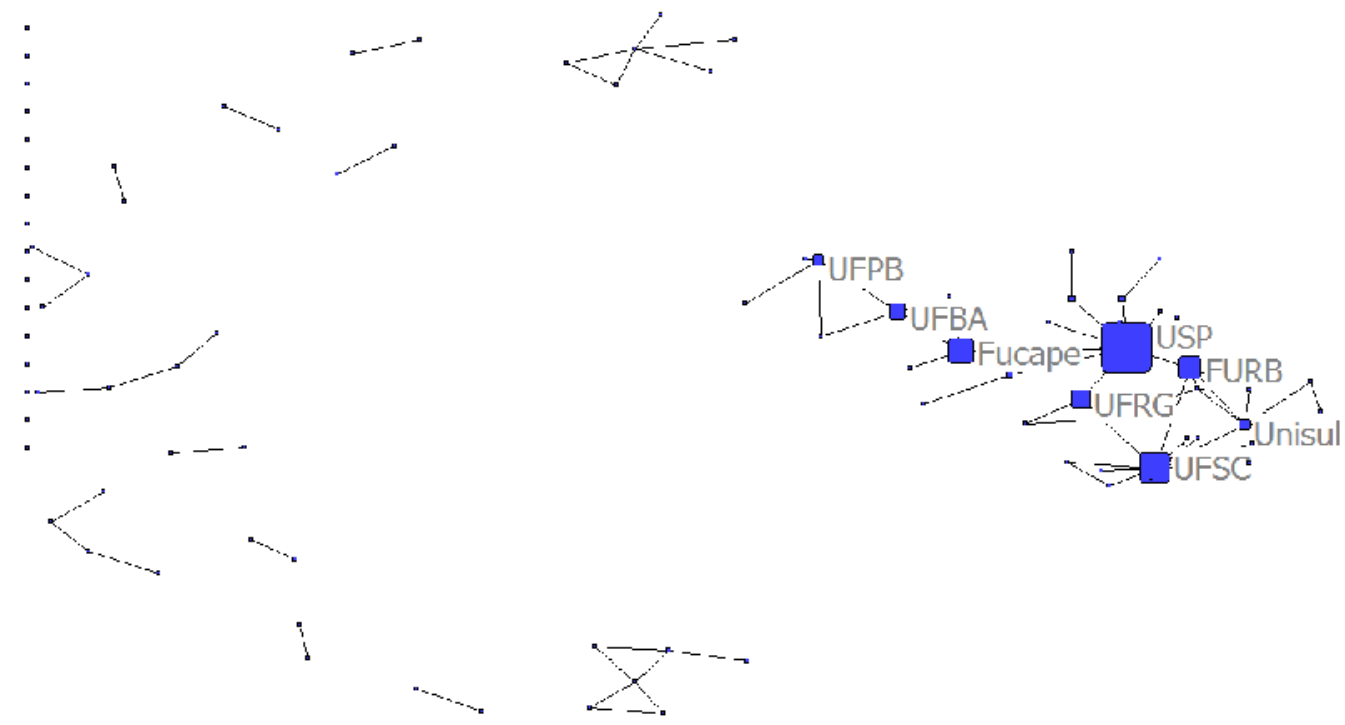

Fonte: Dados da pesquisa.

Sabendo-se que a medida de centralidade de intermediação é definida como a posição em que um autor está na rede, de modo a atuar como intermediador entre outros autores, ou seja, o autor (IESs) se liga a vários outros que não possuem ligações diretas ou, melhor descrevendo, considera o autor como um meio para alcançar diversos outros autores (HANNEMAN; RIDDLE, 2005). A Figura 10 realça as oito IESs com maior centralidade de intermediação neste trabalho, que foram: USP, UFSC, FURB, Fucape, UFRG, UFBA, UFPB e Unisul. Entre elas, destacam-se as IESs USP, UFSC, FURB e Unisul, pois, além de se destacarem como as IESs com maior degree, também estão entre as oito que mais produziram artigos (Figura 5). 
Figura 10 - Centralidade de grau da rede social das IES com a rede social dos autores

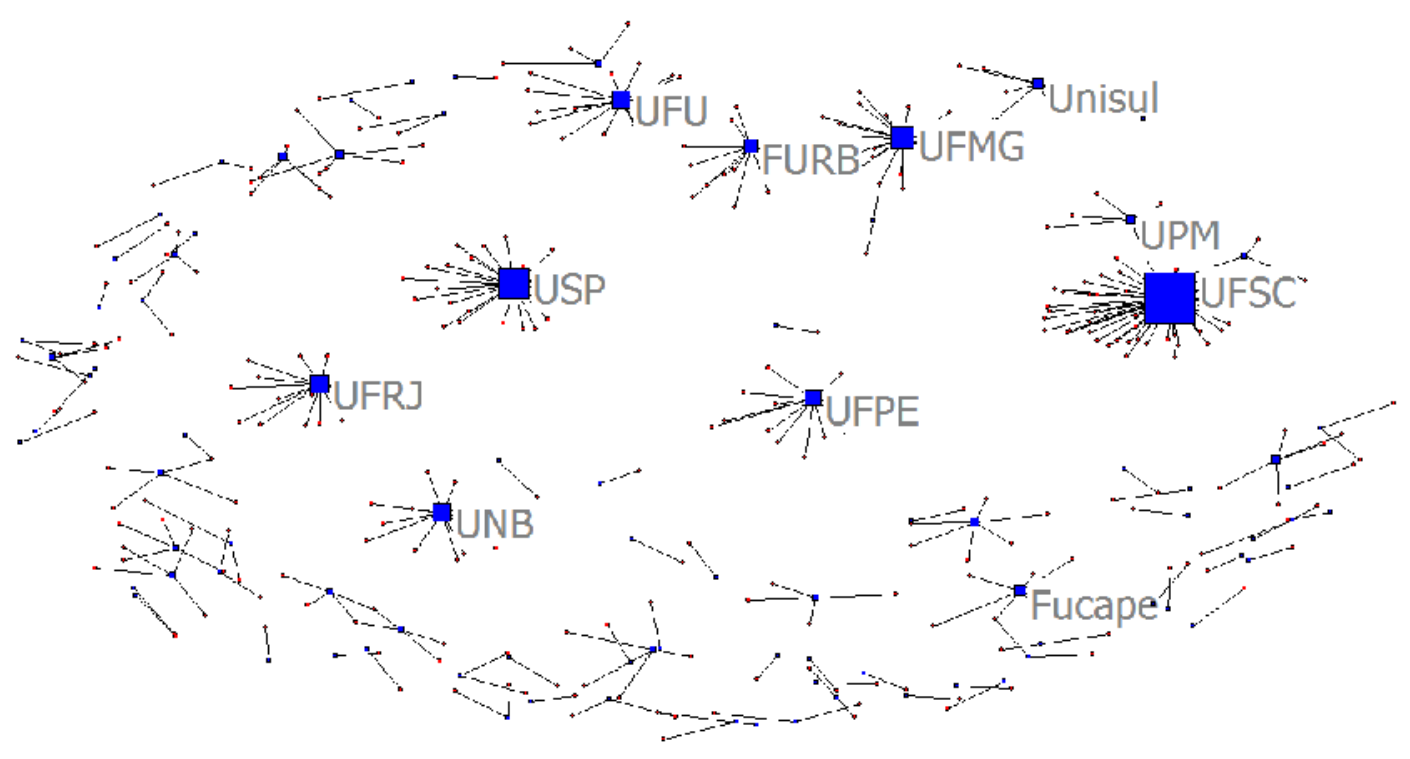

Fonte: Dados da pesquisa.

Já a Figura 10, perece-se o ajuntamento das redes dos autores e das IESs em uma two-mode. Constata-se que as IESs UFSC, USP, UFMG, UNB, UFRJ, UFU, UFPE, FURB, Fucape, Unisul e UPM se destacam nesta pesquisa. É importante realçar que, das 11 IESs evidenciadas na Figura 10, nove aparecem como as que mais publicaram artigos na RCC. Entre essas nove, realçam-se a UFSC e a USP, indo ao encontro do que foi reportado nas Figuras 8 e 9, e considerando-se, assim, as mais importantes deste trabalho.

\subsection{Frequência das palavras-chave}

A Figura 11 visualiza uma nuvem das palavras-chave dos 133 estudos analisados nesta pesquisa.

Figura 11 - Frequência das palavras-chave: no título e nas palavras-chave

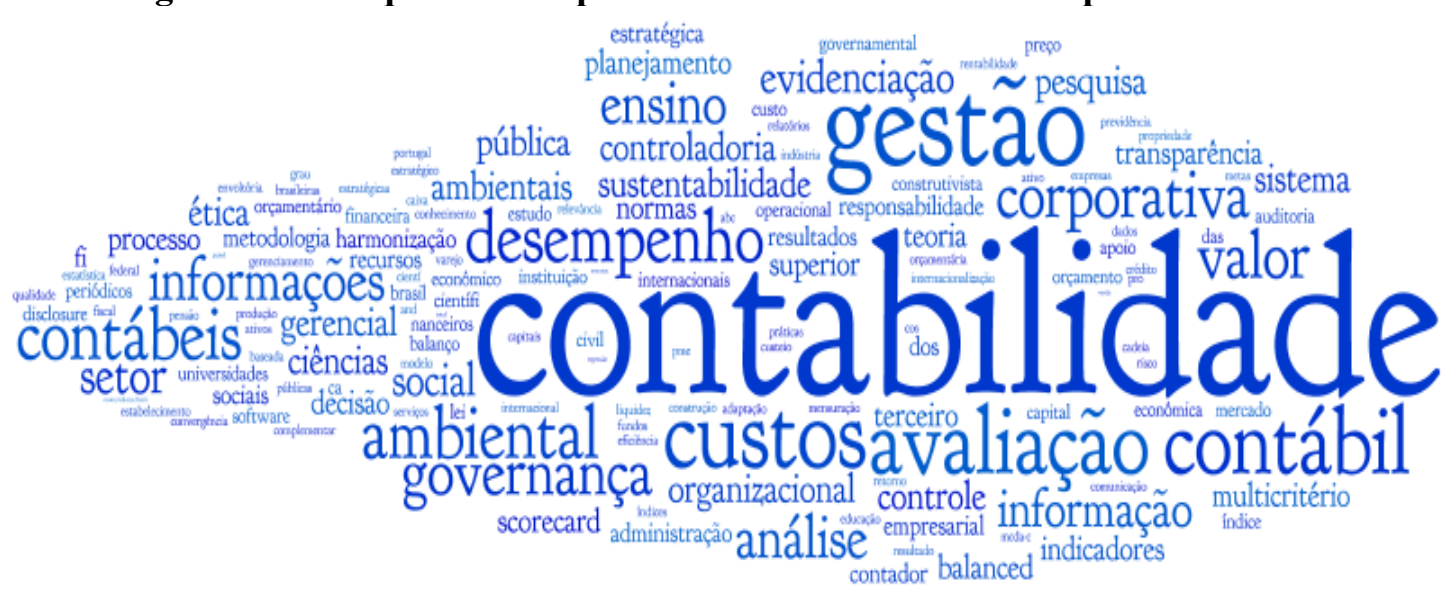

Fonte: Dados da pesquisa.

17 ISSN 2175-8069, UFSC, Florianópolis, v. 10, n. 20, p. 03-28, mai./ago. 2013 
Ressalta-se que a nuvem das palavras-chave é uma forma de visualização de dados linguísticos que mostra a frequência com que as palavras aparecem em determinado contexto (FRANCISCO, 2011). Sendo assim, ficam destacadas as seguintes palavras-chave: contabilidade, gestão, custos, contábil, avaliação, desempenho, corporativa, governança, ambiental, contábeis, informação, ensino, entre outras, o que remete-se à Lei de Zipf, que calcula a frequência de ocorrências das palavras com o intuito de criar e evidenciar o tema científico que é mais contemplado nas pesquisas (EGGHE, 2005).

\subsection{Temas Abordados}

A Tabela 1, a seguir, contempla os 36 temas abordados nos 133 artigos investigados neste estudo.

Tabela 1 - Temas Abordados

\begin{tabular}{|c|c|c|c|c|c|c|c|c|c|c|c|}
\hline Temas/Ano & 2004 & 2005 & 2006 & 2007 & 2008 & 2009 & 2010 & 2011 & 2012 & Total & $\%$ \\
\hline Contabilidade de custos & 2 & 2 & 1 & 1 & 1 & 2 & 2 & 1 & 1 & 13 & 9,77 \\
\hline Ensino e pesquisa & 1 & 1 & & 2 & 1 & 1 & & 5 & 1 & 12 & 9,02 \\
\hline Contabilidade ambiental & & & 2 & 1 & & 3 & 1 & 2 & 1 & 10 & 7,52 \\
\hline Governança corporativa & 1 & & 1 & 1 & 1 & & 2 & 3 & & 9 & 6,77 \\
\hline Contabilidade internacional & 2 & & & & 2 & 1 & 1 & 2 & & 8 & 6,02 \\
\hline Desempenho organizacional & 1 & 1 & 1 & & 1 & 2 & 1 & & 1 & 8 & 6,02 \\
\hline Controladoria & & & 2 & & 2 & & 1 & 1 & 2 & 8 & 6,02 \\
\hline Planejamento orçamentário (governamental) & 1 & & & 1 & 1 & & 1 & & 1 & 5 & 3,76 \\
\hline Balanço social & & 2 & & 2 & & & & & & 4 & 3,01 \\
\hline Ética & & 1 & & & 1 & & 1 & & 1 & 4 & 3,01 \\
\hline Balanced Scorecard & & 1 & & 1 & & & 1 & 1 & & 4 & 3,01 \\
\hline Mercado de capitais & & & & & 1 & & 1 & & 2 & 4 & 3,01 \\
\hline Contabilidade no terceiro setor & 1 & & 1 & & & & & & 1 & 3 & 2,26 \\
\hline Demonstrações contábeis & & 1 & & & & 1 & 1 & & & 3 & 2,26 \\
\hline Transparência/Disclosure & & & 1 & & & 1 & & & 1 & 3 & 2,26 \\
\hline Contabilidade governamental & & & 1 & 1 & & 1 & & & & 3 & 2,26 \\
\hline Estratégia & & 1 & & 1 & 1 & & & & & 3 & 2,26 \\
\hline Informação contábil & & & & 1 & & & 1 & & 1 & 3 & 2,26 \\
\hline Indicadores financeiros & & & & & 1 & 2 & & & & 3 & 2,26 \\
\hline Gestão econômica & 1 & & & 1 & & & & & & 2 & 1,50 \\
\hline Gestão de pessoas & & & 1 & & & 1 & & & & 2 & 1,50 \\
\hline Tecnologia da informação & & & 2 & & & & & & & 2 & 1,50 \\
\hline Administração pública & & & 1 & & & & & & 1 & 2 & 1,50 \\
\hline Contabilidade gerencial & & & 1 & & 1 & & & & & 2 & 1,50 \\
\hline Auditoria & & & & 1 & & & & & 1 & 2 & 1,50 \\
\hline Ativo intangível & 1 & & & & & & & & & 1 & 0,75 \\
\hline Sistema financeiro & & & 1 & & & & & & & 1 & 0,75 \\
\hline Contabilidade agropecuária & & & & 1 & & & & & & 1 & 0,75 \\
\hline
\end{tabular}


Revista Contemporânea de Contabilidade: uma Análise do Perfil da Produção Acadêmica durante o...

\begin{tabular}{|c|c|c|c|c|c|c|c|c|c|c|c|}
\hline Análise de risco & & & & 1 & & & & & & 1 & 0,75 \\
\hline Gestão organizacional & & & & & 1 & & & & & 1 & 0,75 \\
\hline Rentabilidade & & & & & 1 & & & & & 1 & 0,75 \\
\hline Tomada de decisão & & & & & & 1 & & & & 1 & 0,75 \\
\hline Contabilidade financeira & & & & & & & 1 & & & 1 & 0,75 \\
\hline Teoria da contabilidade & & & & & & & 1 & & & 1 & 0,75 \\
\hline Accountability & & & & & & & & 1 & & 1 & 0,75 \\
\hline Profissional contábil & & & & & & & & & 1 & 1 & 0,75 \\
\hline Total & 11 & 10 & 16 & 16 & 16 & 16 & 16 & 16 & 16 & 133 & 100,00 \\
\hline
\end{tabular}

Fonte: Elaborada pelos autores.

A Tabela 1 evidencia os temas Contabilidade de custos, Ensino e pesquisa, Contabilidade ambiental, Governança corporativa, Contabilidade internacional, Desempenho organizacional, Controladoria e Planejamento orçamentário (governamental) como os que mais foram trabalhados pelos autores neste estudo. Os estudos de Perdigão, Niyama e Santana (2010) e Brunozi Júnior et al. (2011) corroboram em parte com essas informações.

Em relação à temática de contabilidade de custos, dentre os subtemas vistos nesta disciplina, o assunto mais visto foi o Custeio ABC, ou seja, o Custeio Baseado em Atividades. Em relação ao tema ensino e pesquisa, a abordagem mais trabalhada foi a pesquisa bibliométrica em artigos de congressos e periódicos, e os congressos onde se trabalhou mais sobre esse tema foram o da ANPAD e ANPCONT.

Já as temáticas governança corporativa e contabilidade internacional são assuntos importantes no cenário nacional e internacional (PERDIGÃO; NIYAMA; SANTANA, 2010), levando em consideração que a RCC é um periódico da área contábil que, ao divulgar trabalhos sobre essas temáticas, auxilia na disseminação do conhecimento desses assuntos, incentivando o crescimento destes na área contábil, por entender que os mesmos se encontram em evidência nos âmbitos corporativo e acadêmico (PERDIGÃO; NIYAMA; SANTANA, 2010). Isso remete ao fato de que a governança corporativa é considerada um mecanismo responsável também por fomentar o desempenho da contabilidade internacional nas organizações (SZÜSTER; SZÜSTER; SZÜSTER, 2005), em especial, aquelas que negociam suas ações em bolsa de valores (SANTOS; COSTA, 2008).

Já os temas desempenho organizacional, controladoria e planejamento orçamentário também se destacaram neste estudo. Contudo, é interessante salientar que os três se integram. Pois a controladoria tem como função fornecer aos gestores das empresas a informação que eles necessitam para atingir seus objetivos, de modo eficaz e eficiente. E o planejamento orçamentário é uma das funções preponderantes da controladoria, dando um norte aos gestores nas tomadas de decisões, impactando, a posteriori, no desempenho da organização (MARTIN, 2002). E uma das ferramentas utilizadas também pela controladoria para otimizar o desempenho empresarial é o Balanced Scorecard (DIETSCHI; NASCIMENTO, 2008), que curiosamente, foi tema base de quatro pesquisas neste estudo na revista ora investigada.

É significativo ressaltar que os temas mais abordados, vistos na Tabela 1, vão ao encontro das palavras-chave mais visualizadas na Figura 11, mostrando, dessa forma, uma relação forte entre os indicadores analisados neste estudo e a Lei de Zipf (EGGHE, 2005).

Ressalva-se também, que os temas Ativo intangível, Sistema financeiro, Contabilidade agropecuária, Análise de risco, Gestão organizacional, Rentabilidade, Tomada 
de decisão, Contabilidade financeira, Teoria da contabilidade, Accountability e Profissional contábil só foram publicados uma vez cada nesse estudo.

\subsection{Abordagens e Métodos de Pesquisa}

Por fim, as Figuras 12 e 13 evidenciam simultaneamente as abordagens e os métodos de pesquisa trabalhados nos 133 artigos investigados neste estudo.

Figura 12 - Abordagens de pesquisa

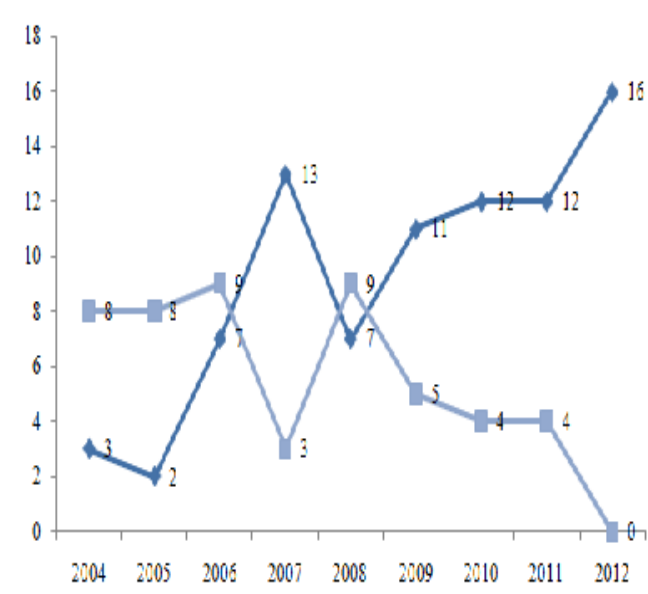

Fonte: Dados da pesquisa.
Figura 13 - Métodos de Pesquisa

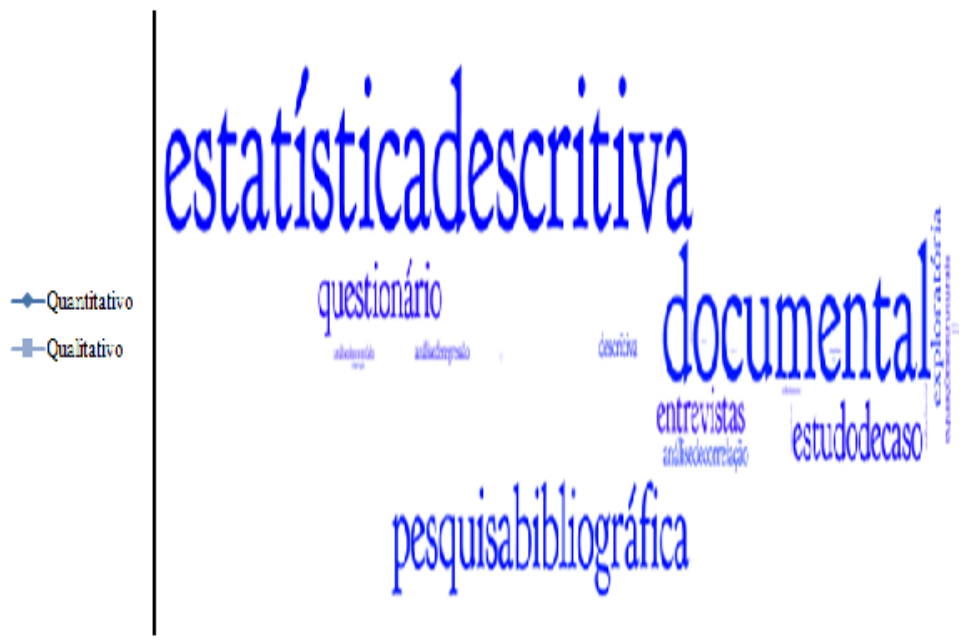

Fonte: Dados da pesquisa.

Analisando a Figura 12, constata-se que a abordagem qualitativa predominou nos três primeiros anos de estudo, voltando a se destacar em 2008. Contudo, a partir de 2009 a abordagem quantitativa começou a se tornar mais evidente, alcançando seu ápice em 2012, com todos os artigos publicados neste ano, adotando a abordagem quantitativa. Complementando a Figura 12, têm-se a Figura 13, a qual aborda os métodos, técnicas e/ou ferramentas de pesquisas adotadas pelos 318 autores analisados neste estudo. Os estudos dos pesquisadores Espejo et al. (2009), Silva, Wanderley e Santos (2010), Dantas et al. (2011) e Ribeiro (2012) confirmam a tendência e a relação forte dos métodos quantitativos com a área contábil.

Observa-se que a estatística descritiva foi o método mais utilizado entre os pesquisadores, seguido da pesquisa documental e do questionário, quando se tratava da abordagem quantitativa. No que tange à abordagem qualitativa, constatou-se que a pesquisa bibliográfica teve predomínio, seguida das técnicas de estudo de caso e entrevistas.

\subsection{Síntese das Análises}

A técnica bibliométrica realizada evidenciou a análise de artigos científicos em termos de oito dimensões evidenciadas no Quadro 1. 
Revista Contemporânea de Contabilidade: uma Análise do Perfil da Produção Acadêmica durante o...

\begin{tabular}{|c|c|c|}
\hline \multicolumn{3}{|c|}{ Quadro 1 - Síntese das análises } \\
\hline Dimensão & Principais resultados & Estudos que corroboram \\
\hline (1) características de autoria & $\begin{array}{l}89,47 \% \text { dos artigos publicados são } \\
\text { de autoria de dois ou mais autores. }\end{array}$ & $\begin{array}{l}\text { Leite Filho e Siqueira (2007) e } \\
\text { Ribeiro (2012). }\end{array}$ \\
\hline (2) autores com maior produção & $\begin{array}{l}\text { Ilse Maria Beuren, Kárem Cristina } \\
\text { de Sousa Ribeiro, Marcelo Alvaro da } \\
\text { Silva Macedo e Romualdo Douglas } \\
\text { Colauto foram os autores que mais } \\
\text { publicaram artigos. }\end{array}$ & $\begin{array}{l}\text { Batistella, Bonacim e } \\
\text { (2008). }\end{array}$ \\
\hline (3) IESs com maior produção & $\begin{array}{l}\text { Universidade Federal de Santa } \\
\text { Catarina e Universidade de São } \\
\text { Paulo são as IESs mais produtivas. }\end{array}$ & $\begin{array}{l}\text { Leite Filho e Siqueira (2007), } \\
\text { Brunozi Júnior et al. (2011), Ribeiro } \\
\text { (2012) e Souza et al. (2012), } \\
\text { principalmente em relação à USP }\end{array}$ \\
\hline (4) redes de coautoria & $\begin{array}{l}\text { Centralizada, com baixa densidade, } \\
\text { sendo que os autores Beuren e } \\
\text { Colauto foram os mais centrais no } \\
\text { que tange ao grau e à intermediação. }\end{array}$ & Francisco (2011) e Ribeiro (2012). \\
\hline (5) rede social das IESs & $\begin{array}{l}\text { Alta centralidade, com baixa } \\
\text { densidade, sendo que as IESs UFSC } \\
\text { e USP foram as que obtiveram maior } \\
\text { centralidade de grau e de } \\
\text { intermediação. }\end{array}$ & Não foram encontrados estudos, \\
\hline (6) frequência das palavras-chave & $\begin{array}{l}\text { Contabilidade, gestão, custos, } \\
\text { contábil, avaliação, desempenho, } \\
\text { corporativa, governança, ambiental, } \\
\text { contábeis, informação e ensino } \\
\text { foram as palavras com maior } \\
\text { frequência de aparecimento. }\end{array}$ & Não foram encontrados estudos. \\
\hline (7) temas abordados & $\begin{array}{l}\text { Contabilidade de custos, ensino e } \\
\text { pesquisa, contabilidade ambiental e } \\
\text { governança corporativa foram os } \\
\text { temais mais abordados nos estudos } \\
\text { explorados. }\end{array}$ & $\begin{array}{l}\text { Perdigão, Niyama e Santana (2010) e } \\
\text { Brunozi Júnior et al. (2011) }\end{array}$ \\
\hline $\begin{array}{l}\text { (8) abordagens e métodos de } \\
\text { pesquisa }\end{array}$ & $\begin{array}{l}\text { A abordagem quantitativa } \\
\text { predominou, juntamente com os } \\
\text { métodos de pesquisa documental e } \\
\text { de estatística descritiva. }\end{array}$ & $\begin{array}{l}\text { Espejo et al. (2009), Silva, } \\
\text { Wanderley e Santos (2010), Dantas } \\
\text { et al. }(2011) \text { e Ribeiro } 2012\end{array}$ \\
\hline
\end{tabular}

Fonte: Dados da pesquisa.

\section{Considerações Finais}

O referido estudo explorou a produção acadêmica da Revista Contemporânea de Contabilidade durante o período de 2004 a 2012. Para tanto, utilizou-se tanto de técnicas de análise bibliométrica, como também da análise de redes sociais. Foram identificados 133 artigos em nove anos de estudo e foram usados os indicadores: (I) características de autoria; (II) autores com maior produção; (III) IESs com maior produção; (IV) redes de coautoria; (V) rede social das IESs; (VI) frequência das palavras-chave; (VII) temas abordados; e (VIII) abordagens e métodos de pesquisa, com a finalidade de responder a questão de pesquisa que tracejou este estudo. Nesse panorama, é importante ressaltar que essas dimensões analisadas 
podem ser fomentadas, incorporando, com isso, dados e informações novas para a área contábil.

Constatou-se que a maioria dos artigos publicados tem parceria com, no mínimo, dois autores, ou seja, 89,47\% dos 133 artigos. Observou-se, também, que os autores Ilse Maria Beuren, Kárem Cristina de Sousa Ribeiro, Marcelo Alvaro da Silva Macedo e Romualdo Douglas Colauto são os pesquisadores mais profícuos, cada um com três artigos publicados. Entre esses autores, destacam-se Beuren e Colauto como os pesquisadores mais centrais deste estudo, tanto no que tange à centralidade de grau, como também à centralidade de intermediação. A Universidade Federal de Santa Catarina é a IES que mais publicou artigos nesses 35 anos de pesquisa. E juntamente com a Universidade de São Paulo, são as IESs com maiores centralidades de grau e de intermediação neste estudo. Embora a UFSC seja a mais prolífica neste estudo e possa remeter a uma endogenia, visto que a revista ora estudada é da própria IES, os autores mais profícuos não têm vínculo nem com a UFSC e nem com a USP. Tal constatação permite afirmar que essas IESs em destaque conseguiram ser predominantes neste estudo por causa da diversidade de autores das revistas analisadas vinculados a essas universidades, contribuindo, assim, para a produção e realce delas neste trabalho.

É bom ressaltar também que, no contexto geral, houve uma quantidade grande de autores (318) em comparação à quantidade de IES (93) envolvidas na publicação dos 133 artigos estudados em nove anos de pesquisa. O número elevado de autores e IES foi preponderante e é inerente aos periódicos que se preocupam com a busca pela diversificação e socialização de opiniões e pontos de vista. O resultado, portanto, vai ao encontro do que foi observado pelos autores Brunozi Júnior et al. (2011), Francisco (2011) e Ribeiro (2012).

Evidenciou-se que os temas Contabilidade de custos, Ensino e pesquisa, Contabilidade ambiental, Governança corporativa, Contabilidade internacional, Desempenho organizacional, Controladoria e Planejamento orçamentário (governamental) foram os que se destacaram na temporalidade de nove anos de pesquisa, representando $54,89 \%$ do total dos 133 artigos analisados. Tal dado vai ao encontro das principais palavras-chave visualizadas nesses artigos, que foram contabilidade, gestão, custos, contábil, avaliação, desempenho, corporativa, governança, ambiental, contábeis, informação e ensino. Salienta-se a importância desses temas para a área contábil, pois os mesmos (principalmente os temas contabilidade ambiental, governança corporativa e contabilidade internacional) estão em franco crescimento nas publicações dos periódicos Qualis da área de Administração, Contabilidade e Finanças no Brasil.

Este estudo contribuiu, dessa forma, para atingir o objetivo proposto, além de apresentar uma agenda para pesquisa sobre contabilidade contemporânea sob a ótica da RCC, com base nos 133 trabalhos identificados. Outra contribuição é para o avanço e aperfeiçoamento dos papers sobre contabilidade contemporânea no meio acadêmico. Salientase que os achados deste estudo contribuirão na emergência, disseminação e otimização desse tema para a literatura acadêmica nacional, proporcionando, a posteriori, a possibilidade de surgimento e aperfeiçoamento de grupos de pesquisa que possibilitaram uma melhor reflexão sobre como é a contabilidade contemporânea.

Conclui-se, de maneira geral, que o acervo da Revista Contemporânea de Contabilidade reflete o universo da produção acadêmica da área contábil, ajudando, assim, a desenvolver, disseminar e socializar a área por meio de artigos científicos publicados na literatura acadêmica nacional. 
Entende-se como fator limitador desta pesquisa a quantidade de artigos analisados, e sugere-se, para futuras pesquisas, uma análise mais aprofundada dos temas abordados por meio de uma análise de conteúdo, além de uma otimização das técnicas de análise de rede social, trabalhando tanto a centralidade de proximidade (Closeness), como os nós e laços dos autores de maneira individual e consolidada.

\section{Referências}

ACEDO, F. J.; CASILLAS, J. C. Current paradigms in the international management field: an author co-citation analysis. International Business Review, v. 14, p. 619-639. 2005.

AMBONI, N.; CAMINHA, D. O.; ANDRADE, R. O. B. de. Produção acadêmica em teoria neo-institucional no Brasil: 1990 a 2010. Revista Gestão e Planejamento, v. 13, n. 2, p. 212231. 2012.

BARBOSA, E. T. et al. Uma análise bibliométrica da Revista Brasileira de Contabilidade no período de 2003 a 2006. In: CONGRESSO USP DE CONTROLADORIA E

CONTABILIDADE, 8., 2008, Rio de Janeiro. Anais... CONGRESSOUSP, 2008. Disponível em: <http://www.congressousp.fipecafi.org/artigos82008/618.pdf > . Acesso em: 18 fev.2013.

BATISTELlA, F. D.; BONACIM, C. A. G.; MARTINS, G. de A. Contrastando as produções da Revista Contabilidade \& Finanças (FEA-USP) e Revista Base (Unisinos). Revista de Educação e Pesquisa em Contabilidade, v. 2, n. 3, p. 84-101. 2008.

\section{BEUREN, I. M.; LONGARAY, A. A. Como elaborar trabalhos monográficos em contabilidade: teoria e prática. São Paulo: Atlas, 2003.}

BEUREN, I. M.; PINTO, J.; ZONATTO, V. C. da S. Abordagens da controladoria nos trabalhos do congresso USP de Controladoria e Contabilidade: um enfoque nas perspectivas conceitual, procedimental e organizacional. Revista Contemporânea de Contabilidade, v. 9, n. 17, p. 03-16. 2012.

BRUNOZI JÚNIOR, A. C. et al. Revista Contabilidade \& Finanças - USP: uma análise do perfil da produção científica de 1989 a 2009 . Revista Universo Contábil, v. 7, n. 4, p. 39-59. 2011.

CARDOSO, R. L. et al. Pesquisa científica em contabilidade entre 1990 e 2003. Revista de Administração de Empresas, v. 45, n. 2, p. 34-45. 2005.

CARNEIRO, A. de F. et al. Custos na administração pública: revisão focada na publicação de artigos científicos a partir da promulgação da Lei de Responsabilidade Fiscal. Revista

Contemporânea de Contabilidade, v. 9, n. 18, p. 03-22. 2012. 
CELLA, G.; RODRIGUES, J. M.; NIYAMA, J. K. Contabilidade internacional - análise dos periódicos internacionais sobre pesquisas em educação contábil face à convergência e globalização. Revista Contemporânea de Contabilidade, v. 8, n. 15, p. 177-198. 2011.

CHAMBERS, E. A. An introduction to meta-analysis with articles from the journal of educational research (1992-2002). The Journal of Educational Research, v. 98, n. 1, p. 3544. 2004.

COELHO, P. S.; SILVA, R. N. S. da. Um estudo exploratório sobre as metodologias empregadas em pesquisas na área de contabilidade no Enanpad. Revista Contemporânea de Contabilidade, v. 1, n. 8, p. 139-159. 2007.

CRUZ, A. P. C. da. et al. Perfil das redes de cooperação científica: congresso USP de controladoria e contabilidade - 2001 a 2009. Revista Contabilidade \& Finanças, v. 22, n. 55, p. 64-87. 2011.

DANTAS, J. A. et al. Padrões de comunicação científica em contabilidade: um comparativo entre a Revista Contabilidade e Finanças e a The Accounting Review. Revista

Contemporânea de Contabilidade, v. 8, n. 16, p. 11-36. 2011.

DIAS, W. de O.; BARBOSA NETO, J. E.; CUNHA, J. V. A. da. A comunicação do conhecimento científico: dados sobre a celeridade do processo de avaliação e de publicação de artigos científicos em periódicos da área de contabilidade. Revista Contemporânea de Contabilidade, v. 8, n. 15, p. 41-62. 2011.

DRIKSSON, A. La sociedad del conocimiento desde la perspectiva latinoamericana. Centro de Estudios sobre la Universidad, Universidad Autónoma de México, 2000.

DIETSCHI, D. A.; NASCIMENTO, A. M. Um estudo sobre a aderência do Balanced Scorecard às empresas abertas e fechadas. Revista Contabilidade \& Finanças, v. 19, n. 46, p. 73-85, 2008.

EGGHE, L. Zipfian and lotkaian continuous concentration theory. Journal of the American Society for Information Science and Technology, v. 56, n. 9, p. 935-945. 2005.

ESPEJO, M. M. dos S. B. et al. Estado da arte da pesquisa contábil: um estudo bibliométrico de periódicos nacional e internacionalmente veiculados entre 2003 e 2007 . Revista de Informação Contábil, v. 3, n. 3, p. 94-116. 2009.

FERREIRA, M. P. A bibliometric study on ghoshal's managing across borders. The Multinational Business Review, v. 19, n. 4, p. 357-375. 2011.

FRANCISCO, E. de R. RAE-eletrônica: exploração do acervo à luz da bibliometria, geoanálise e redes sociais. Revista de Administração de Empresas, v. 51, n. 3, p. 280-306. 2011. 
FREEMAN, L. C. Social networks and the structure experiment. Research Methods in Social Network Analysis, p. 11-40, 1989.

FREEMAN, L. C. Social networks and the structure experiment. In: L. C. Freeman, D. R.; White.;K. A. Romney (Eds.). Research methods in social network analysis. New Brunswick, NJ: Transaction Publishers, pp. 11-40, 1992.

GNYAWALI, D.; MADHAVAN, R. Cooperative networks and competitive dynamics: a sctrutural embeddedness perspective. Academy of Management Review, v. 26, n. 3, p. 431445. 2001.

GONZALO, O. M. et al. Análisis bibliométrico de la revista de economía institucional en sus primeros diez años. Revista de Economía Institucional, v. 11, n. 20, p. 309-353. 2009.

GUARIDO FILHO, E. R.; MACHADO-DA-SILVA, C. L.; GONÇALVES, S. A.

Organizational institutionalism in the academic field in Brazil: social dynamics and networks.

Brazilian Administration Review, v. 6, n. 4, p. 299-315. 2009.

GUARIDO FILHO, E. R.; MACHADO-DA-SILVA, C. L.; GONÇALVES, S. A. The development of institutional theory in the field of organization studies in Brazil. Cadernos EBAPE.BR, v. 8, n. 2, p. 279-301. 2010.

HANNEMAN, R. A.; RIDDLE, M. Introduction to Social Network Methods. Riverside: University of California, 2005.

LATAPY, M.; MAGNIEN, C.; DEL VECCHIO, N. Basic notions for the analysis of large two-mode networks. Social Networks, v. 30, n. 1, p. 31-48. 2008.

LEITE FILHO, G. A.; SIQUEIRA, R. L. Revista Contabilidade \& Finanças USP: uma análise bibliométrica de 1999 a 2006. Revista de Informação Contábil, v. 1, n. 2, p. 102-119. 2007.

MARTIN, N. C. Da contabilidade à controladoria: a evolução necessária. Revista Contabilidade \& Finanças, v. 13, n. 28, p. 7-28. 2002.

MELI, D. B.; OLIVEIRA NETO, J. D. de. O perfil da colaboração nos periódicos contábeis nacionais: muitos one-timers e poucos continuants. Revista Contemporânea de Contabilidade, v. 8, n. 15, p. 151-176. 2011.

MOREIRA, O.; RICCIO, E. L.; SAKATA, M. C. G. A comunicação de informações nas instituições públicas e privadas: o caso XBRL extensible business reporting language in Brazil. Revista de Administração Pública, v. 41, n. 4, p. 769-784. 2007.

NERUR, S. P.; RASHEED, A. A.; NATARAJAN, V. The intellectual structure of the strategic management field: an author co-citation analysis. Strategic Management Journal, v. 29, p. 319-336. 2008. 
OLIVEIRA, M. C. Análise dos periódicos brasileiros de contabilidade. Revista Contabilidade \& Finanças, v. 13, n. 29, p. 68-86. 2002.

PERDIGÃO, L. Z.; NIYAMA, J. K.; SANTANA, C. M. Contabilidade, gestão e governança: análise de doze anos de publicação (1998 a 2009). Contabilidade, Gestão e Governança, v. 13, n. 3, p. 3-16. 2010.

RAMOS-RODRÍGUEZ, A. R.; RUÍZ-NAVARRO, J. Changes in the intellectual structure of strategic management research: a bibliometric study of the strategic management journal, 1980-2000. Strategic Management Journal, v. 25, p. 981-1004. 2004.

REVISTA CONTEMPORÂNEA DE CONTABILIDADE (RCC). Foco e escopo. Disponível em:

$<$ http://www.periodicos.ufsc.br/index.php/contabilidade/about/editorialPolicies\#focusAndSco pe>. Acesso em: 08 fev. 2013.

REVISTA CONTEMPORÂNEA DE CONTABILIDADE (RCC). Referência Qualis CAPES. Disponível em:

$<$ https://periodicos.ufsc.br/index.php/contabilidade/about/editorialPolicies\#custom-0>. Acesso em: 08 fev. 2013.

RIBEIRO, H. C. M. Brazilian Business Review: um estudo sob a ótica da bibliometria e da rede social de 2004 a 2011. Revista de Gestão, Finanças e Contabilidade, v. 2, n. 3, p. 86104. 2012.

RICHARDSON, R. J.; PERES, J. A. de S. Pesquisa social: métodos e técnicas. São Paulo: Atlas, 1989.

ROSSONI, L.; HOCAYEN-DA-SILVA, A. J.; JÚNIOR, I. F. Aspectos estruturais da cooperação entre pesquisadores no campo de administração pública e gestão social: análise das redes entre instituições no Brasil. Revista de Administração Pública, v. 42, n. 6, p. 1041-1067. 2008.

ROWE, D. E. O.; BASTOS, A. V. B. Vínculos com a carreira e produção acadêmica: comparando docentes de IES públicas e privadas. Revista de Administração Contemporânea, v. 14, n. 6, p. 1011-1030. 2010.

SANTOS, L. S. R. dos; COSTA, F. M. da. Conservadorismo contábil e timeliness: evidências empíricas nas demonstrações contábeis de empresas brasileiras com ADRs negociadas na bolsa de Nova Iorque. Revista Contabilidade \& Finanças, v. 19, n. 48, p. 27-36. 2008.

SCOTT, J. Social network analysis: a handbook. 2. ed. London: Sage Publications, 2000.

SEBASTIÁN, J. Analisis de las redes de investigacion de America Latina con la Unión Europea. Revista de Ciência e Tecnologia, v.3, n. 2, p. 308-321. 1999. 
SILVA, A. C. da; WANDERLEY, C. A. N.; SANTOS, R. dos. Utilização de ferramentas estatísticas em artigos sobre contabilidade financeira: um estudo quantitativo em três congressos realizados no país. Revista Contemporânea de Contabilidade, v. 1, n. 14, p. 1128. 2010.

SOUZA, F. J. V. de. et al. Revista de Contabilidade do Mestrado em Ciências Contábeis da UERJ: uma análise de oito anos de publicação (2003 a 2011). Revista de Administração, Contabilidade e Sustentabilidade, v. 2, n. 3, p. 69-85. 2012.

SOUZA, J. V. de; PETRI, S. M.; CARDOSO, M. de S. Uma contribuição à avaliação dos periódicos científicos por meio do Balanced Scorecard: ilustração da avaliação e operacionalização da gestão estratégica na RCC. Revista Contemporânea de Contabilidade, v. 8 , n. 15 , p. 87-104. 2011.

SZÜSTER, N.; SZÜSTER, F. R.; SZÜSTER, F. R. Contabilidade: atuais desafios e alternativa para seu melhor desempenho. Revista Contabilidade \& Finanças, v. 16, n. 38, p. 20-30. 2005.

TOMAÉL, M. I.; MARTELETO, R. M. Redes sociais: posições dos atores no fluxo da informação. Revista Eletrônica de Biblioteconomia e Ciência da Informação, n. 1, p. 75 91, 2006.

WASSERMAN, S.; FAUST, K. Social network analysis: methods and applications. Cambridge: Cambridge University Press, 1994. 
